\title{
Morfologia externa de Parastacus brasiliensis (Decapoda, Parastacidae)
}

\author{
Ana Cristina M. Horn, Ludwig Buckup, Clarissa K. Noro \& Daniela F. Barcelos
}

Programa de Pós-Graduação em Biologia Animal, Departamento de Zoologia, Instituto de Biociências, UFRGS. Av. Bento Gonçalves, 9500, Prédio 43435, 91501-970 Porto Alegre, RS, Brasil. (anahorn@ig.com.br; lbuckup@yahoo.com.br)

\begin{abstract}
External morphology of Parastacus brasiliensis (Decapoda, Parastacidae). Parastacus brasiliensis (von Martens, 1869) is an endemic South Brazilian freshwater crayfish that occurs in the river systems belonging to the Guaíba estuary, in the central lowlands of the state of Rio Grande do Sul. The aim of this study is to describe and illustrate the external morphology and the distribution of the different types of setae on the appendages of adult P. brasiliensis. In laboratory, the specimens were dissected and the details of the morphological organization described and drawn with a camara lucida adapted to a stereomicroscope. A scanning electron microscope was utilized for a more detailed study of the setae. The results were compared with other crayfish species and also with the juvenile stages of $P$. brasiliensis. The types and the distributional pattern of the setae observed are similar to Austropotamobius pallipes (Lereboullet, 1858). Differences were found in the basipodite and the coxopodite of the first maxilliped and in the first maxilla of $P$. brasiliensis, where the serrate setae are replaced by the plumodenticulate and multidenticulate forms.
\end{abstract}

KEYWORDS. Appendages, crayfish, setae.

RESUMO. Parastacus brasiliensis (von Martens, 1869) é um lagostim de água doce endêmico da região meridional brasileira, ocorrendo nas bacias que formam o estuário do Guaíba, na depressão central do Estado do Rio Grande do Sul. O objetivo deste estudo é descrever e ilustrar a morfologia externa e a distribuição dos diferentes tipos de setas nos apêndices de exemplares adultos de $P$. brasiliensis. Em laboratório, os exemplares foram dissecados e detalhes da organização morfológica foram descritos e ilustrados com auxílio de câmara clara adaptada ao estereomicroscópio. Microscopia eletrônica de varredura foi utilizada para um melhor detalhamento no estudo das setas. Os resultados obtidos foram comparados com outras espécies de lagostins e com estágios juvenis de P. brasiliensis. Os tipos de setas e o padrão de distribuição observados são similares ao encontrado em Austropotamobius pallipes (Lereboullet, 1858). Diferenças foram encontradas no basipodito e no coxopodito do primeiro maxilípodo e na primeira maxila de $P$. brasiliensis, onde setas serradas são substituídas por formas plumodenticuladas e multidenticuladas.

PALAVRAS-CHAVE. Apêndices, lagostins, setas.

Desde que Poeppig (1835) descreveu a primeira espécie de lagostim límnico do hemisfério meridional, sob a denominação de Astacus pugnax, estes crustáceos foram objeto de estudos morfológicos genéricos aplicáveis à sistemática e à taxonomia, com destaque para HuXLey (1879), FAXON (1898, 1914), RIEK (1971, 1972), Hoвbs $(1974,1987)$ e Buckup \& Rossi $(1980,1993)$.

O conhecimento da morfologia dos diferentes tipos de setas que revestem o corpo dos crustáceos deve-se aos estudos de Thomas (1970), Fish (1972), FARmer (1974), Drach \& Jacques (1977), JACQues (1989), Watling (1989), Calazans \& Ingle (1998) e Garm et al. (2003). Todos os autores argumentaram que o sistema setal pode constituir importante fonte de informações de interesse ecológico, especialmente no que se refere à função das peças bucais.

Inúmeros trabalhos foram desenvolvidos com o propósito de investigar a morfologia e a função desempenhada pelos apêndices dos crustáceos. HuXLEY (1879) descreveu as antenas como principal órgão táctil em lagostins. MatтHes (1952) descreveu as antenas de Astacus fluviatilis Linnaeus, 1758, atualmente Astacus astacus (Linnaeus, 1758). AMEYAw-AKumfi \& HaZLetT (1975) observaram tufos de sensilas quimiorreceptoras nas quelas do primeiro e segundo par de patas de Procambarus clarkii (Girardi, 1852). McLaughlin (1982) comparou as peças bucais de diversos grupos de crustáceos e WALES (1982) confrontou a morfologia das peças com a sua possível função na manipulação do alimento. Wiernicki (1984) apud Holdich \& ReEve (1988) destacam a importância do arranjo de setas em P. clarkii e seu papel na filtração da água para a captura de alimento. BAUER (1989) revisou a morfologia funcional dos apêndices raspadores de crustáceos decápodos e Holdich (2002) estudou a morfologia externa dos lagostins, descrevendo todos seus apêndices e suas funções.

Na Região Neotropical, onde ocorrem dez espécies de lagostins parastacídeos, destacam-se estudos sobre aspectos da morfologia externa relacionados ao significado funcional da existência de gonóporos de ambos os sexos no mesmo indivíduo (RUDOLPH, 1990, 1997, 1999; AlMEIDA \& BuCKuP, 1997, 1999, 2000). Estudos morfológicos dos estágios juvenis e das setas do adulto de P. brasiliensis, espécie endêmica do Rio Grande do Sul, foram recentemente realizados por NoRO et al. (2005) e HORN \& BUCKUP (2004).

Neste contexto, o exame mais detalhado da morfologia de $P$. brasiliensis em seu estágio adulto apresentou-se como forma de preenchimento de uma lacuna no conhecimento da história natural dos crustáceos límnicos. Além disso, diante da semelhança na macromorfologia das espécies neotropicais de parastacídeos, é necessário conhecer com maior detalhamento a organização morfológica da espécie, objetivando futuros estudos evolutivos com as demais espécies do grupo. 


\section{MATERIAL E MÉTODOS}

Os exemplares estudados procedem da bacia hidrográfica do rio Gravataí, na nascente do arroio Mineiro, localidade de Fazenda Fialho, Taquara (2946'S, 5053'W), Rio Grande do Sul, Brasil. Os exemplares machos descritos (cinco exemplares) foram depositados na coleção de crustáceos do Departamento de Zoologia da UFRGS. Os espécimes, com medidas entre 80 a 90mm de comprimento da carapaça cefalotorácica, foram coletados com armadilhas de PVC no ano de 2001.

Exemplares adultos de $P$. brasiliensis tiveram as antenas, peças bucais, pereiópodos, pleópodos, télson e urópodos dissecados para observação e, juntamente com o cefalotórax e o abdômen, foram descritos e representados graficamente com o auxílio de câmara clara adaptada ao estereomicroscópio.

As setas nos apêndices foram observadas em estereomicroscópio e microscópio óptico e, quando necessário, contou-se com imagens obtidas em microscópio eletrônico de varredura do Centro de Microscopia Eletrônica da UFRGS, utilizando-se a técnica adaptada de Scotto (1980) e Felgenhauer (1987). Os tipos setais encontrados foram classificados de acordo THOMAS (1970).

\section{RESULTADOS E DISCUSSÃO}

A morfologia de $P$. brasiliensis é semelhante à que foi descrita por MATTHes (1952) para a espécie européia Astacus fluviatilis. A região da carapaça sobre o coração (aréola) é delimitada pelos sulcos branquiocárdicos, que correm paralelos entre si e perpendiculares ao sulco cervical, sendo que a ausência de uma sutura mediana longitudinal na carapaça foi usado por HoвBs (1988) para caracterizar os parastacídeos sul-americanos.

Rostro triangular, projetado até a extremidade distal do penúltimo artículo da antena. Duas cristas paralelas se prolongam na superfície cefalotorácica (Fig. 1) e pequenas setas paposas cobrem toda a borda da carapaça. Nas faces antero-laterais da carapaça surgem concavidades junto a pequenos tubérculos, as quais VoGT (2002) denominou de "pit-organs", que seriam receptores hidrodinâmicos de ordem sensorial.

Segmentos abdominais cobertos por pequenas concavidades semelhantes às descritas para a carapaça. Pleura do primeiro segmento abdominal mais curta do que as subseqüentes, parcialmente encoberta pela pleura do segundo segmento. Superfície marginal das pleuras 1 a 6 com pequenas setas paposas, mais densamente distribuídas nas margens laterais (Fig. 2). Placa esternal com quilha mediana estreita, que se estende da região anterior do coxopodito do primeiro pereiópodo até a base do coxopodito do quarto pereiópodo (Fig. 3).

Antênula ou $1^{\text {a }}$ antena (Fig. 4). Formada por 3 artículos (protopodito triarticulado). Artículo basal o maior, com contorno retangular, aloja na região centrobasal (face dorsal da peça) o estatocisto, no qual encontram-se numerosas setas paposas; margem oral com setas paposas nas regiões basal e distal. Margem aboral com setas paposas em toda a extensão, menos numerosas na região distal, onde encontra-se um grupo de 10-12 setas multidenticuladas. Face ventral da peça, próximo à margem oral mediana, com um pequeno espinho.

Artículo central cilíndrico, com as margens cobertas por setas paposas crescentes em direção à extremidade distal, onde são longas, principalmente na margem apical oral. Margem apical aboral com um grupo de setas simples e paposas. Artículo distal cilíndrico-globoso; margens cobertas por setas paposas a partir da região mediana. Região oral-apical com setas simples e paposas. Do ápice deste artículo partem dois flagelos multissegmentados: um externo maior (exopodito, 59-66 segmentos) e um interno menor (endopodito, 41-47 segmentos). No flagelo externo, até dois terços da base, há de 1 a 3 estetascos em cada artículo, distribuídos sempre nas margens apicais e esse número aumenta na porção mais distal do flagelo para grupos de até 6 . Pequenas setas simples também podem estar localizadas entre os estetascos. No flagelo interno, os segmentos são mais delgados, com pequenas setas simples que podem variar de 1 a 4 nos primeiros dois terços do flagelo e até 6 nos mais apicais.

Os estetascos já haviam sido observados por vários autores (HuXley, 1879; MATTHEs, 1952; THOMAS, 1970). Vogt (2002) informou que se trata de mecanorreceptores que reagem a vibrações pouco intensas na água. Noro et al. (2005) verificaram que os estetacos já podem ser observados no juvenil 2 de $P$. brasiliensis.

Antena ou $2^{a}$ antena (Fig. 5). Coxa e base fusionados, formando protopodito grande e assimétrico com setas paposas na margem médio-distal interna. $\mathrm{O}$ exopodito tem forma foliácea achatada dorsoventralmente, constituindo a escama antenal. Margem externa retilínea terminando em um espinho robusto com pequenas setas simples distribuídas por toda sua extensão. Margem interna convexa com longas setas plumosas. Endopodito bissegmentado. Artículo proximal subcilíndrico com um grupo de setas ocupando a margem oral a partir do terço distal. Artículo distal com pequenas setas paposas sobre as laterais e tufos maiores em toda margem apical. Deste artículo parte o flagelo antenal, multissegmentado, podendo conter mais de cem segmentos. A maioria dos segmentos do flagelo é dotada de pequenas setas simples, 1-3 em cada uma das margens laterais. Noro et al. (2005) observaram que a formação destas setas ocorre somente no juvenil 3 .

Mandíbula (Fig. 6). Processo incisivo esclerotinizado, com nove dentes robustos e assimétricos. Processo molar com três dentes assimétricos. Superfície do processo incisivo (superfície aboral da peça) com algumas setas multidenticuladas localizadas na região posterior formando um pequeno tufo próximo aos dentes. Palpo mandibular trisegmentado. Regiões marginais médio-distais do artículo basal com dois tufos de setas paposas. Artículo mediano com inúmeras setas paposas na margem externa, junto ao ponto de inserção com o artículo basal. Artículo distal, na sua região de inserção, com tufo de setas paposas e o restante das margens densamente coberta por setas "teazel". A presença dessas setas no palpo mandibular também foi verificada em A. pallipes por ThomAs (1970) e podem ser observadas no segundo estágio juvenil de $P$. brasiliensis (Noro et al., 2005). 
De acordo com FACTOR (1989), que compara o desenvolvimento do aparato alimentar nos decápodos, nos Astacidea, Thalassinidea e Palinura, não há mandíbulas cortantes nos estágios larvais, como foi observado no primeiro e segundo estágios de $P$. brasiliensis por Noro et al. (2005).

Primeira maxila (Fig. 7). Endopodito afilado e bissegmentado. Ápice do segmento distal com seis a sete setas cuspidadas e ao longo do segmento, cerca de dez setas plumodenticuladas. Região apical do segmento proximal, na margem interna, com pequeno grupo de setas serradas e poucas setas multidenticuladas longas na margem oral. Margem aboral com um tufo de setas paposas na região basal. Basipodito do protopodito robusto e com margem aboral coberta por longas setas multidenticuladas. Extensão da margem oral com setas plumodenticuladas e multidenticuladas na região mais basal. Margem apical do basipodito com setas cuspidadas robustas e superfície com setas plumodenticuladas. Thomas (1970) encontrou no basipodito de A. pallipes setas serradas ("serruladas"), que não foram observadas em P. brasiliensis. Já a presença das longas setas multidenticuladas que foram notadas no basipodito de $P$. brasiliensis, não foram mencionadas em A. pallipes.

Margem distal do coxopodito com setas "teazel". Setas plumodenticuladas e multidenticuladas na região proximal da margem interna; restante da superfície com setas plumodenticuladas. Região basal do protopodito com tufos de setas paposas e outro de setas multidenticuladas.

No segundo estágio juvenil de $P$. brasiliensis é possível observar inúmeras setas cuspidadas no basipodito e "teazel" no coxopodito (Noro et al., 2005). WARNER (1977) descreveu a maxila como apêndice achatado, que tem seus exopoditos perdidos; possuem enditos desenvolvidos em sua margem medial que são usados para segurar e manipular o alimento.

Segunda maxila (Fig. 8). Aspecto foliáceo. Exopodito (escafognatito) alongado, desenvolvido, com setas paposas na margem. Margem inferior com aproximadamente cinco setas multidenticuladas. Superfície do escafognatito com pequenas setas conadas e algumas setas-gancho na região inferior. Endopodito alongado e afilado próximo à porção distal, com setas paposas na margem aboral inferior. Margem oral com quinze setas plumodenticuladas. Basipodito e coxopodito com dois lobos, o do basipodito com setas simples em sua margem distal. Setas plumodenticuladas nas margens e superfícies médio-distais marginais. Região basal dos enditos com setas multidenticuladas. Lobos do coxopodito menores, de localização mais oral. Lobos com setas "teazel" e plumodenticuladas nas margens láteroapicais. Superfície médio-distal dos lobos com setas multidenticuladas e plumodenticuladas.

KAESTNER (1980) indica que a maxila é usada para o transporte de alimento até a mandíbula ou para filtração dos alimentos; para WARNER (1977), a segunda maxila é de grande significância, devido à presença do escafognatito, que é essencial na respiração por impulsionar a água para dentro da câmara branquial.

Primeiro maxilípodo (Fig. 9). Epipodito foliáceo alongado. Superfície oral na região médio-distal com filamentos branquiais tubulares. Superfície do epipodito com setas-gancho. Protopodito formado por dois lobos com aspecto foliáceo. Lobo proximal (coxopodito) menor, com setas paposas cobrindo toda a metade anterior; lobo distal maior e subtriangular (basipodito). Margem distal e subdistal densamente cobertas com setas simples e margens laterais com setas plumodenticuladas e multidenticuladas. Em A. pallipes, Thomas (1970) encontrou neste artículo setas serradas ("serruladas"), que não foram observadas em P. brasiliensis. Endopodito alongado, foliáceo e reduzido. Margem lateral apical, do lado aboral, com inúmeras setas paposas; restante deste artículo desprovido de setas. Exopodito alongado e dividido em região basal e em flagelo. Margens laterais da região basal do exopodito com setas paposas. Flagelo multiarticulado a partir da região mediana e com setas plumosas na margem apical.

Segundo maxilípodo (Fig. 10). Região basal longa, coberta por setas paposas e simples. Flagelo multissegmentado com longas setas plumosas concentradas da região médio-distal para o ápice. Epipodito dirigido para a cavidade branquial, onde forma uma podobrânquia. $\mathrm{Na}$ articulação deste apêndice com o corpo, se situa uma artrobrânquia. Endopodito pentarticulado. Região oral do protopodito com setas paposas e plumodenticuladas. Restante do artículo revestido com setas simples e paposas. Isquiopodito coberto por pequenos grupos de longas setas simples na região oral. Meropodito retangular, alongado e achatado dorsoventralmente; face oral coberta por robustas setas serradas e por uma grande quantidade de setas simples. Setas simples se distribuem por todo o artículo e pequenas setas paposas concentram-se mais na região basal do meropodito. Carpopodito desprovido de setas. Própodo assimétrico, com setas simples e serradas na margem aboral superior. Margem superior aboral com tufo de setas serradas e na região mais apical, próximo à inserção do dactilopodito, dois tufos de setas simples. Dactilopodito subcilíndrico, com setas simples e cuspidadas na região apical e subapical. Cinco a seis setas cuspidadas se encontram na região mais apical e estão associadas com seis a dez cuspidadas com dentes, que são bem menores que as anteriores. Thomas (1970), ao descrever este mesmo apêndice em A. pallipes, também observou que a associação de robustas setas cuspidadas com outras de menor tamanho e que apresentavam pequenas denticulações só ocorria neste determinado local.

Terceiro maxilípodo (Fig. 11). Endopodito desenvolvido e pentarticulado. Epipodito se estende para a cavidade branquial formando uma podobrânquia. Duas artrobrânquias estão inseridas na sua articulação. Basipodito com setas simples, paposas e plumodenticuladas na superfície anterior. Exopodito formado por dois artículos: o primeiro é alongado, com setas simples e paposas na sua face aboral. A partir dele se prolonga um flagelo formado por pequenos segmentos e com setas plumosas. Isquiopodito achatado e retangular. Margem oral com crista dentada de aproximadamente 20 dentes robustos e irregulares com setas simples longas no lado interno; tal formação já havia sido observada por McLaughlin (1982) em Astacidea, Palinura e Anomura. Região basal do isquiopodito com setas paposas e simples. Do lado oposto à implantação 

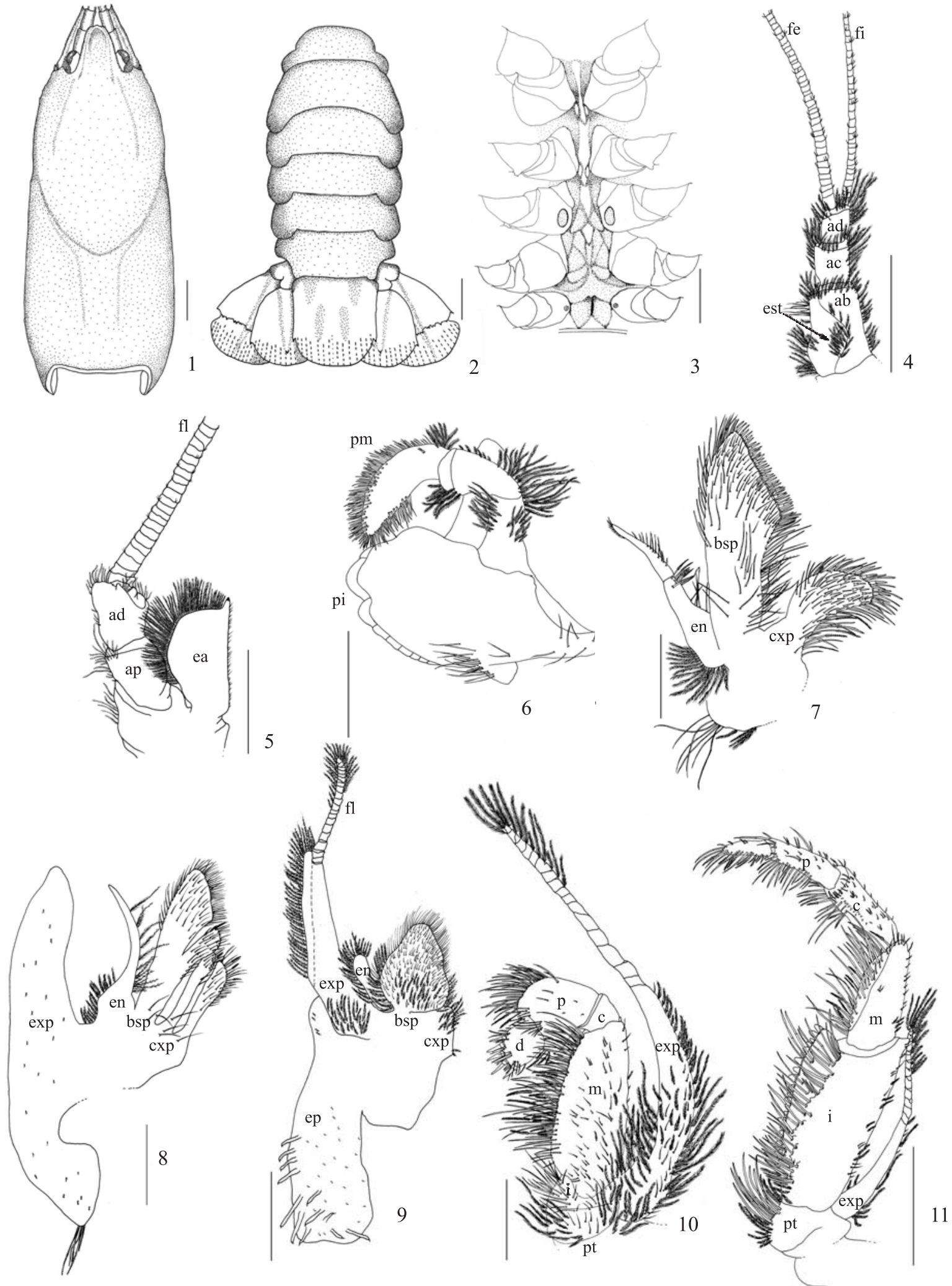

Figs. 1-11. Parastacus brasiliensis (von Martens, 1869): 1, cefalotórax, dorsal; 2, abdômen, dorsal; 3, região torácica, ventral; 4, primeira antena, dorsal; 5, segunda antena, dorsal; 6, mandíbula, aboral; 7, primeira maxila; 8, segunda maxila; 9, primeiro maxilípodo; 10, segundo maxilípodo; 11, terceiro maxilípodo. (ab, artículo basal; ac, artículo central; ad, artículo distal; ap, artículo proximal; bsp, basipodito; c, carpopodito; cxp, coxopodito; d, dactilopodito; ea, escama antenal; en, endopodito; ep, epipodito; est, estatocisto; exp, exopodito; fe, flagelo externo; fi, flagelo interno; fl, flagelo; i, isquiopodito; m, meropodito; p, propodito; pi, processo incisor; pm, processo molar; pt, protopodito). Escalas, Figs. 1-5, 8, 9, 11:5mm; Fig. 6:3mm; Figs. 7, 10:2,5mm. 
da crista dentada existem pequenas setas simples, paposas e serradas, que formam uma fileira nessa lateral. Meropodito subtriangular com margem aboral com pequenas setas simples; margem oral com setas serradas menores e setas simples longas. Carpopodito cilíndrico, achatado dorsoventralmente e superfície com alguns tufos de pequenas setas simples e paposas. Margem oral com setas simples e predominância de setas serradas. Própodo cilíndrico e superfície com pequenas setas simples e setas serradas, localizadas na margem oral. Margem aboral com setas simples. Dactilopodito subcilíndrico, com setas serradas na margem oral; na margem aboral se encontram em menor número, juntamente com as setas simples.

O terceiro par de maxilípodos pode adquirir função na busca e ingestão de alimentos (Budd et al., 1979 apud Holdich \& ReEve, 1988) e na limpeza dos restos alimentares. Os lagostins podem gerar um fluxo de água corrente para obter alimentos por meio do batimento dos exópodos dos maxilípodos e um filtro é formado por uma fileira de setas existentes no segundo e terceiro maxilípodos (Budd et al., 1979 apud Holdich \& REeve, 1988). Para WARNER (1977), os maxilípodos - juntamente com outras peças bucais - são usados exclusivamente para manipular o alimento.

Primeiro pereiópodo (Fig. 12). Protopodito formado pelo coxopodito - porção mais quadrangular - e basipodito e isquiopodito fusionados, subtriangular e maior que o coxopodito. Meropodito sub-retangular. Própodo robusto e forma distalmente um dedo fixo que se articula com um dedo móvel, o dáctilo, formando uma quela desenvolvida. Na região basal do coxopodito, está inserida uma podobrânquia e são encontradas duas artrobrânquias na articulação. Margem dorsal do coxopodito com tufo de setobrânquias, que também estão presentes nos demais pereiópodos; margem ventral com setas multidenticuladas. Lado externo da articulação coxa/ base-ísquio com uma protuberância desenvolvida, semelhante a um espinho e com poucas setas multidenticuladas; o restante desta margem não possui setas. Margem interna com pequenos tubérculos e setas multidenticuladas reduzidas. Restante do segmento desprovido de setas.

Margem interna do meropodito com tubérculos com aspecto de serrilha e com setas paposas e simples. Tubérculos perdem o aspecto serrilhado na margem externa. Carpopodito com poucos tubérculos na superfície, restritos à face ventral e à margem aboral. Associações de setas simples e paposas observadas somente na base dos tubérculos. Face dorsal do carpopodito com pequenas concavidades de onde partem setas simples e paposas, o que AmeYAw-AkUmfi \& HAZLETT (1975) chamaram de sensilas quimiorreceptoras, que seriam comuns a todos os lagostins.

Pinça robusta, formada pelo propodito e dactilopodito, com tubérculos e setas paposas na superfície de oclusão de ambos os dedos. A região proximal termina com uma unha apical.

Segundo pereiópodo (Fig. 13). Epipodito com uma podobrânquia e duas artrobrânquias; ambas com setas multidenticuladas na base de inserção. Na inserção da podobrânquia parte um tufo de setobrânquias. Região basal do epipodito com muitas setas paposas pequenas. Protopodito com dois artículos: coxopodito - que porta um tufo de setobrânquias - e basipodito e ísquiopodito fusionados. Basipodito e ísquiopodito com formato semicilíndrico, revestido na margem ventral de tufos de pequenas setas simples associadas com setas multidenticuladas maiores. Margem dorsal com setas simples e paposas concentradas na região basal, até o terço médio da peça. Meropodito alongado com margens cobertas por pequenas setas simples. Carpopodito triangular, alongado e achatado dorsoventralmente com setas simples nas margens. Própodo achatado, formando com o dactilopodito (dedo móvel) uma pinça que termina numa unha apical. Superfície ventral e dorsal do própodo e do dactilopodito coberta por tufos de pequenas setas simples. Margem de oclusão entre o dactilopodito e o propodito coberta por setas dentiformes, conferindo a essa margem um aspecto serrilhado.

Terceiro pereiópodo (Fig. 14). Epipodito com o mesmo número de brânquias do segundo pereiópodo. A forma dos artículos é muito semelhante, mas pode-se destacar algumas diferenças: margens com os mesmos tipos de setas, mas em menor número que as margens do própodo. Ventralmente, na base do coxopodito encontrase o poro genital feminino (Fig. 15a) de contorno ovóide, que pode estar total ou parcialmente obstruído, dependendo da fase sexual do animal. Setas paposas e simples contornam a região marginal dos poros. Região dorsal do coxopodito com um tufo de setobrânquias.

Quarto pereiópodo (Fig. 16). Epipodito com uma podobrânquia e duas artrobrânquias, sendo uma delas vestigial. Segmentos proximais similares, obedecendo ao mesmo padrão dos dois anteriores, mas com algumas diferenças: o apêndice termina com um dactilopodito simples, que forma uma unha apical, e não uma quela. Própodo com tufos de setas simples em sua superfície e com setas serradas. Dactilopodito com tufos de setas simples e margem ventral com setas dentiformes.

Quinto pereiópodo (Fig. 17). Brânquias ausentes em sua articulação basal. É semelhante aos demais, mas os densos tufos de setas serradas do própodo estão mais restritos à margem ventral do que no quarto pereiópodo. Ventralmente, na base do coxopodito, há o poro genital masculino (Fig. 15b), de dimensões mais reduzidas que o feminino e formando uma pequena protuberância. Ao redor dos poros, setas simples e paposas se distribuem e, dorsalmente no coxopodito, observam-se setobrânquias.

Nos juvenis 1 e 2, dactilopodito do quarto e quinto pereiópodos terminando na forma de um gancho, que é utilizado pelos juvenis para se fixar nas setas dos pleópodos das fêmeas. Após a muda, no terceiro estágio juvenil, este gancho é perdido e substituído por uma unha apical (Noro et al., 2005).

Pleópodo (Figs. 18-21). Em P. brasiliensis, como nos demais parastacídeos, tanto machos como fêmeas não possuem pleópodos no primeiro somito abdominal (Horwitz, 1988). Inseridos do segundo ao quinto segmento abdominal, os quatro pares de pleópodos têm formato semelhante, sendo a única diferença observada uma diminuição de tamanho em ordem crescente. Margens do protopodito com setas simples; em uma das margens, 
há um tufo de setas plumosas, localizado próximo à inserção do endopodito. Do protopodito partem o endopodito e o exopodito que têm um aspecto mais achatado e não-tubular. Endopodito de posição distal e levemente maior que o exopodito, de posição proximal, ambos cobertos por setas plumosas.

Télson (Fig. 22). Margens laterais retilíneas, terminando em um espinho. Margem distal entre os dois espinhos convexa, formando um semicírculo e densamente coberta por setas distribuídas em duas fileiras: a primeira, mais dorsal, formada por setas simples e a segunda, mais ventral, por setas plumosas. Margens laterais com setas plumosas, reduzidas. Pequenas setas simples e paposas distribuídas ao longo do apêndice, formando pequenos tufos de até cinco setas. O ânus abre-se na região basal e ventral do télson.

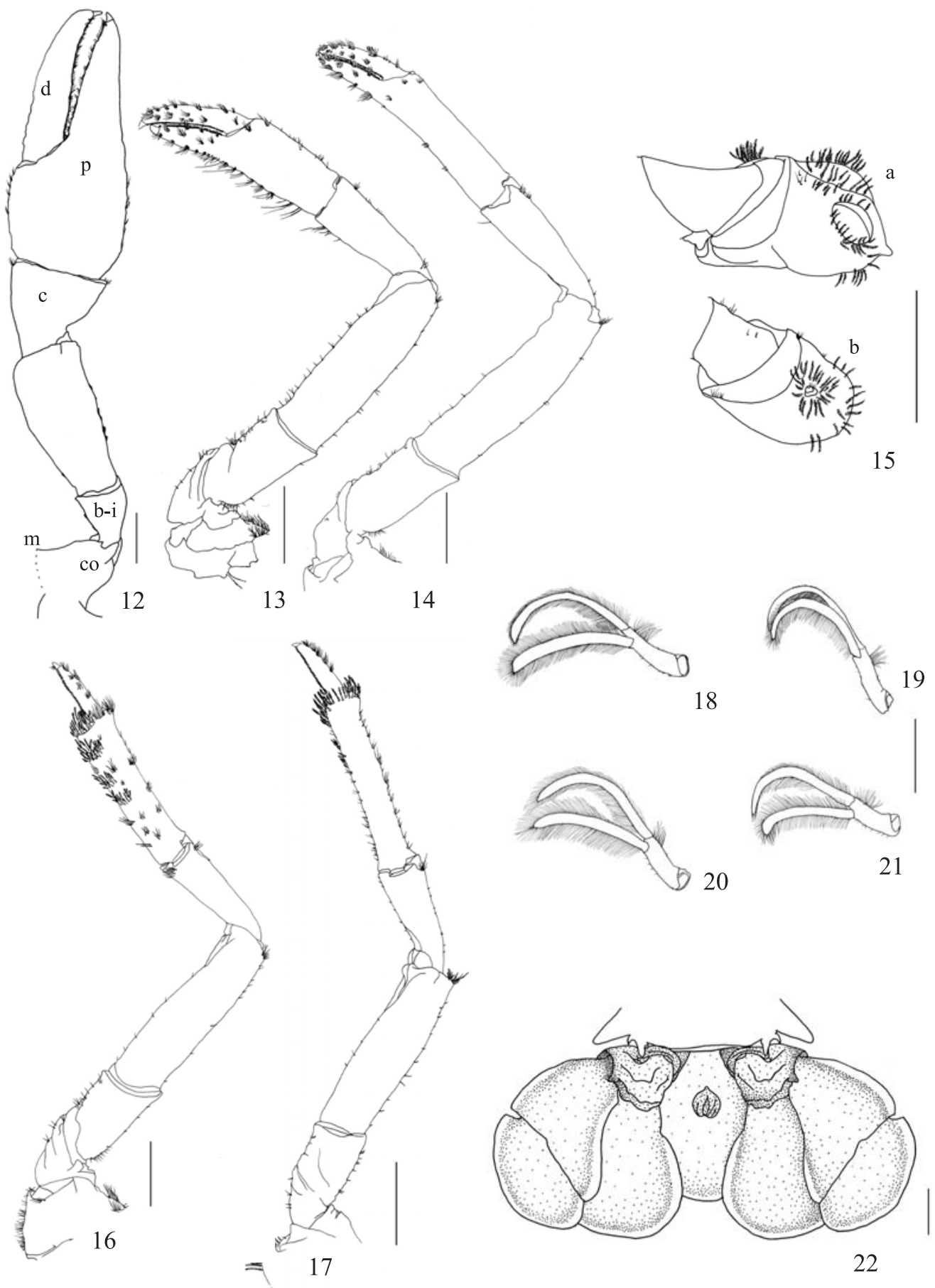

Figs. 12-22. Parastacus brasiliensis (von Martens, 1869): 12, primeiro pereiópodo; 13, segundo pereiópodo; 14, terceiro pereiópodo; 15, coxopodito do (a) terceiro e (b) quinto pereiópodos; 16, quarto pereiópodo; 17, quinto pereiópodo; 18, primeiro pleópodo; 19, segundo pleópodo; 20, terceiro pleópodo; 21, quarto pleópodo; 22, leque caudal (c, carpopodito; d, dactilopodito; m, meropodito; p, propodito; b-i, base/ísquio; co, coxopodito). Escalas, $5 \mathrm{~mm}$. 
Urópodos (Fig. 22). O protopodito dos urópodos forma um pequeno lobo com margem em dois semicírculos. Pequenas setas simples e paposas em toda a região, inclusive nas margens. Endopodito com região basal mais estreita que a distal e dois espinhos desenvolvidos visíveis: um deles na região mediana, no terço mais distal e outro no final da margem externa. Essa margem é coberta por setas plumosas e simples que, como no télson, formam duas fileiras. Na margem lateral externa não há setas e, na lateral interna, as tem a partir da metade distal. Na região ântero-lateral interna encontram-se setas paposas pequenas encobertas pela margem externa do télson.

Exopodito, assim como o endopodito, com região basal reduzida, dando à peça um contorno semicircular. Nesta altura da margem externa, há um espinho robusto; daí até a outra margem segue-se uma fileira de espinhos pequenos, visíveis, que podem ter uma pequena variação de tamanho e se intercalam a setas simples e paposas pequenas. Porção distal do artículo em forma de uma meia lua, de margem distal convexa, toda coberta por grandes setas plumosas dispostas em uma fileira ventral e setas simples em fileira dorsal. Margem lateral externa com a mesma disposição de setas, enquanto a margem lateral interna é desprovida de setas. Superfície dorsal do exopodito coberta por tufos de setas simples e paposas; superfície ventral desprovida de setas.

A morfologia, disposição e tipos de setas encontradas no leque caudal de $P$. brasiliensis assemelhase às descrições feitas para outros lagostins (MATthEs, 1952; Thomas, 1970). No juvenil, os urópodos só são formados no terceiro estágio juvenil e, juntamente com o télson, formam o leque caudal ornamentado com grande quantidade de setas simples e plumosas (Noro et al., 2005).

\section{CONCLUSÕES}

A morfologia dos apêndices de $P$. brasilienis segue o padrão básico já descrito para outras espécies de crustáceos (MATTHes, 1952; HuXley, 1879; HoBbs, 1987, 1988). Os tipos e o padrão de distribuição das setas de $P$. brasiliensis segue o já descrito para A. pallipes por Thомаs (1973), diferenciando-se, porém, no basipodito e coxopodito do primeiro maxilípodo e primeira maxila, onde não foram encontradas setas serradas, mas sim plumodenticuladas e multidenticuladas.

Observa-se que a morfologia do adulto é muito similar àquela do juvenil ao eclodir, porém pode-se verificar algumas diferenças: (1) os ganchos apicais no dactilo dos pereiópodos 4 e 5 estão presentes nos juvenis 1 e 2 e são substituídos por uma unha apical nos adultos; (2) ausência dos urópodos que só são formados no juvenil 3; (3) ausência de setas no juvenil 1, com exceção do exopodito da maxila 2 e primeiro maxilípodo; (4) no juvenil 2 observa-se uma grande variedade de setas, porém em menor número do que nos adultos; (5) no juvenil 3 pode-se observar toda a variedade de formas setais encontradas no adulto mas em menor número (Noro et al., 2005).

Um método indireto para estudar a função dos apêndices é por meio da análise da sua morfologia. É importante ressaltar a importância dos apêndices bucais na obtenção e manipulação do alimento, o que pode ser constatado pelo grande número e variedade de setas presentes nestes apêndices. A predominância de uma categoria de setas em um apêndice indica sua função principal. A coleta do alimento é executada pelos dois primeiros pares de pereiópodos e a existência de tufos de sensilas quimiorreceptoras nestes apêndices, já observado em Procambarus clarkii (AMEYAW-AKumfi \& Hazlett, 1975), confirma esta função. Para auxiliar no processo de alimentação, as setas podem atuar no desgaste do material (função exercida principalmente pelas setas serradas, cuspidadas e conadas); direcionar o alimento em direção a abertura bucal (ex: "teazel" e setas multidenticuladas); coleta e transferência de partículas (setas multidenticuladas, denticuladas, paposas e plumosas) e detecção química das partículas, principalmente pelos estetascos localizados nas antênulas (Thomas, 1970; FARMER, 1974; MARTin \& Felgenhauer, 1986).

Outra função das setas é aumentar a área dos apêndices e melhorar seu desempenho, como nos pleópodos, urópodos, exopoditos dos maxilípodos e exopodito antenal, onde longas setas plumosas atuam como remos que auxiliam na natação. Nas maxílulas, maxilas e primeiros maxilípodos, as setas também atuam na prevenção da entrada de partículas para a câmara branquial e os exopoditos ajudam a criar uma corrente de água entre as peças bucais e na filtragem de partículas (ThOMAS, 1970; FARMER, 1974; MARTIN \& FelgenhaUer, 1986).

Agradecimentos. Ao M.Sc. Luiz Carlos Campos Daudt, pelo auxílio na edição das pranchas.

\section{REFERÊNCIAS BIBLIOGRÁFICAS}

Almeida, A. O. \& Buckup, L. 1997. Aspectos anatômicos e funcionais do aparelho reprodutor de Parastacus brasiliensis (von Martens) (Crustacea, Decapoda, Parastacidae). Revista Brasileira de Zoologia 14(2):497-509.

1999. Caracteres sexuais primários e secundários do lagostim Parastacus defossus Faxon, 1898 (Crustacea, Parastacidae). Nauplius 7:113-126.

2000. Occurrence of protandric hermaphroditism in a population of the neotropical freshwater crayfish Parastacus brasiliensis (Parastacidae). Journal of Crustacean Biology 20(2):224-230.

Ameyaw-Akumfi, C. \& Hazlett, B. A. 1975. Sex recognition in the crayfish Procambarus clarkii. Science 190:1225-1226.

Bauer, R. T. 1989. Decapod crustacean grooming: functional morphology, adaptive value, and phylogenetic significance. In: Felgenhauer, B.; Watling, L. \& Thistle, R. eds. Functional morphology of feeding and grooming in Crustacea. Crustacean Issues. v.6. Rotterdam, A. A. Balkema. p.49-73.

Buckup, L. \& Rossi, A. 1980. O gênero Parastacus no Brasil (Crustacea, Decapoda, Parastacidae). Revista Brasileira de Biologia 40(4):663-681.

1993. Os Parastacidae do espaço meridional andino (Crustacea, Astacidea). Revista Brasileira de Biologia 53(2): 167-176.

Calazans, D. \& Ingle, R. 1998. The setal morphology of the larval phases of the Argentinean red shrimp Pleoticus muelleri Bate, 1888 (Decapoda: Solenoceridae). Invertebrate Reproduction and Development 33(2-3):109-126.

Drach, P. \& JACQues, F. 1977. Système sétifère des crustacés décapodes: Principes d'une classification générale. Comptes Rendus de l' Academie des Sciences 284:1995-1998.

FACTOR, J. R. 1989. Development of the Feeding Apparatus in Decapod Crustaceans. In: Felgenhauer, B.; Watling, L. \& Thistle, R. eds. Functional morphology of feeding and 
grooming in Crustacea. Crustacean Issues. v.6. Rotterdam, A. A. Balkema. p.185-203.

FARMER, A. S. 1974. The functional morphology of the mouthparts and pereiopods of Nephrops norvegicus (L.) (Decapoda: Nephropidae). Journal of Natural History 8:121-142.

FAXON, W. 1898. Observations on the Astacidae in the United States National Museum and in the Museum of Comparative Zoology, with descriptions of new species. Proceedings of United States National Museum 20:643-694.

1914. Notes on the crayfishes in the United States National Museum and the Museum of Comparative Zoology with descriptions of new species and subspecies to wich is append a catalogue of the known species and subspecies. Memories of the Museum of Comparative Zoology of Harvard College 40(8):351-427.

Felgenhauer, B. E. 1987. Techniques for preparing crustaceans for scanning eletron microscopy. Journal of Crustacean Biology 7(1):71-76.

Fish, S. 1972. The setae of Eurydice pulchra (Crustacea: Isopoda). Journal of Zoology 166:163-177.

Garm, A.; Hallberg, E. \& Hoeg, J. T. 2003. Role of maxilla 2 and its setae during feeding in the shrimp Palaemon adspersus (Crustacea, Decapoda). Biological Bulletin 204:126-137.

HobBs, H. H. JR. 1974. Synopsis of the families and genera of crayfishes (Crustacea: Decapoda). Smithsonian Contributions to Zoology 164:1-32.

1987. A Review of the Crayfish Genus Astacoides (Decapoda: Parastacidae). Smithsonian Contributions to Zoology 443:1-50.

1988. Crayfish distribution, adaptive radiation and evolution. In: Holdich, D. M. \& Lowery, R. S. eds. Freshwater crayfish: biology, management and exploitation. Portland, Timber. p. $52-82$.

Holdich, D. M. 2002. Background and functional morphology. In: Holdich, D. M. ed. Biology of freshwater crayfish. London, Blackwell Science. p.3-29.

Holdich, D. M. \& ReEve, I. D. 1988. Functional morphology and anatomy. In: Holdich, D. M. \& Lowery, R. S. eds. Freshwater crayfish: biology, management and exploitation. Portland, Timber. p.11-51.

Horn, A. C. M. \& Buckup, L. 2004. Morfologia setal de Parastacus brasiliensis (von Martens) (Crustacea, Decapoda, Parastacidae). Revista Brasileira de Zoologia 21(4):765-768.

Horwitz, P. 1988. Secundary sexual characteristics of females of the freshwater crayfish genus Engaeus (Decapoda, Parastacidae). Crustaceana 54(1):25-32.

Huxley, T. H. 1879. The crayfish. An introduction to the study of Zoology. Kegan Paul, London, Cambridge. 371p.

JACQUES, F. 1989. The setal system of crustaceans: types of setae, groupings, and functional morphology. In: Felgenhauer, B. E.; Watling, L. \& Thistle A. B. eds. Functional morphology of feeding and grooming in Crustacea. Crustacean Issues. v.6. Rotterdam, A. A. Balkema. p.1-13.
Kaestner, A. 1980. Invertebrate Zoology III. Huntington, Robert E. Krieger. 523p.

Martin, J. W. \& Felgenhauer, B. E. 1986. Grooming behaviour and the morphology of grooming appendages in the endemic South American crab genus Aegla (Decapoda, Anomura, Aeglidae). Journal of Zoology 209:213-224.

Matthes, E. 1952. Guia de trabalhos práticos de zoologia. Coimbra, Universidade de Coimbra. 426p.

McLaughlin, P. A. 1982. Comparative morphology of crustacean appendages. In: ABELE, L. G. ed. The biology of Crustacea: embryology, morphology, and genetics. v.2. New York, Academic. p.197-256.

Noro, C. K.; Buckup, L. \& Bond-Buckup, G. 2005. The juvenile stages of Parastacus brasiliensis (von Martens, 1869) (Crustacea, Decapoda, Parastacidae). Journal of Natural History 39(21):1851-1873.

Poeppig, E. 1835. Reise in Chile, Peru und auf dem Amazonasstrome während der Jahre 1827-1832. 1:1-466.

RIEK, E. 1971. The freshwater crayfishes of South America. Proceedings of the Biological Society of Washington 84(16): 129-136.

1972. The phylogeny of the Parastacidae (Crustacea, Astacoidea), and description of a new genus of Australian freshwater crayfishes. Australian Journal of Zoology 20:369-389.

Rudolph, E. H. 1990. Caracteres sexuales externos del camarón excavador, Parastacus nicoleti (Philippi, 1882). Biota 6:19-34 1997. Intersexualidad en el camarón excavador Parastacus pugnax (Poeppig, 1835) (Decapoda, Parastacidae). Investigaciones Marinas 25:7-18.

. 1999. Intersexuality in the freshwater crayfish Samastacus spinifrons (Philippi, 1882) (Decapoda, Parastacidae). Crustaceana 72:325-337.

Scotto, L. E. 1980. Studies on Decapod Crustacea from the Indian River Region of Florida. XIV: a method for rapid preparation of Brachyuran larval for scanning electron microscopy. Crustaceana 38(1):99-101.

Thomas, W. J. 1970. The setae of Austropotamobius pallipes (Crustacea: Astacidae). Journal of Zoology 160:91-142. 1973. The hatchling setae of Austropotamobius pallipes (Lereboullet) (Decapoda, Astacidae). Crustaceana 24:77-89.

Vogt, G. 2002. Functional Anatomy. In: Holdich, D. M. ed. Biology of freshwater crayfish. London, Blackwell Science. p.53-151.

Wales, W. 1982. Control of mouthparts and gut. In: Atwood, H. L. \& Sandeman, D. C. eds. The biology of Crustacea: neural integration and behavior. v.4. New York, Academic. p.165-191.

Warner, G. F. 1977. The Biology of Crabs. New York, Van Nostrand Reinhold Company. 202p.

WAtLing, L. 1989. A classification system for crustacean setae based on the homology concept. In: Schram, F. R. ed. Functional morphology of feeding and grooming in Crustacea. Crustacean Issues. v.6. Rotterdam, A. A. Balkema. p.15-26.

Recebido em junho de 2006. Aceito em julho de 2007. ISSN 0073-4721

Artigo disponível em: www.scielo.br/isz 